\title{
Injection ranitidine induced death
}

\author{
S. Anandhi*, R. Mani \\ Department of Pharmacology, Coimbatore Medical College, Tamil Nadu, India \\ Received: 04 March 2020 \\ Accepted: 07 April 2020 \\ *Correspondence: \\ Dr. S. Anandhi, \\ Email: doc.anandhi@mail.com \\ Copyright: (c) the author(s), publisher and licensee Medip Academy. This is an open-access article distributed under \\ the terms of the Creative Commons Attribution Non-Commercial License, which permits unrestricted non-commercial \\ use, distribution, and reproduction in any medium, provided the original work is properly cited.
}

\begin{abstract}
Ranitidine is a histamine-2-receptor antagonist. It was a commonly used drug. It holds excellent safety record. Anaphylactic reactions to ranitidine is uncommonly encountered. Death due to ranitidine is extremely a rare event and very few cases are reported world-wide. Clinical history, Lab investigations and histological data of a 43-Years old woman with negative history of allergic events, who died suddenly after the intra-venous administration of 50mg of intravenous ranitidine which was prescribed as a routine pre medication prior hysterectomy is presented below. Though the incidence of anaphylactic reactions is less with ranitidine, precautions to be taken prior administration of the drug and when such an event is encountered it should be promptly managed.
\end{abstract}

Keywords: Ranitidine, Anaphylaxis, Death, Safety

\section{INTRODUCTION}

Ranitidine hydrochloride belongs to histamine-2-receptor antagonist (H2RA). It was commonly used orally as well as parenterally in the treatment of pepticulcer, acute stress ulcers, GERD in medical departments and as preanesthetic medication, during surgery, during post op recovery in surgical departments and in intensive care units.

Ranitidine has an excellent safety record apart from minor anaphylactic reactions reported all over and very few reports of fatalities reported so far. Symptoms such as malaise, dizziness, somnolence, insomnia and vertigo have been reported so far. Rare events such as reversible mental confusion, agitation, depression and hallucinations have also been reported. Symptoms pertaining to cardiovascular system include cases of tachycardia, bradycardia, atrio-ventricular block and premature ventricular beats. ${ }^{1}$ There have been reports of hepatocellular injury. These events are usually reversible, but in rare circumstances death has occurred. Also reported are cases of pancytopenia, marrow hypoplasia, agranulocytosis and immune haemolytic anemia. ${ }^{1}$ This case report highlights the occurrence of death due to ranitidine injection which is extremely a very rare event.

\section{CASE REPORT}

43-year-old female was admitted for complaints of menorrhagia in the Department of Obstetrics and Gynaecology in Coimbatore Medical College Hospital. Patient had no history of allergy to drugs, food or any other products. Patient underwent routine blood and urine tests. Her CBC, blood sugar, renal and liver function tests were normal. Chest Xray, ECG, ECHO was also normal. Patient was diagnosed to have sub mucosal fibroid of size $6 \times 5 \times 5 \mathrm{cms}$ by ultra-sonogram three units of packed cells was transfused to her on alternate days with careful watch during transfusion since her haemoglobin was $7 \mathrm{gm} \%$ on admission and she was continued with haematinics later on. Patient was posted for Fractional Curettage, ten days after admission after completion of necessary investigations. Pre op ranitidine medication was not given prior fractional curettage. Biopsy after fractional curettage was reported as Benign Endometrial hyperplasia. 
Patient was planned for total hysterectomy with bilateral salpingo oophorectomy. On the day of surgery, Inj. Ranitidine $50 \mathrm{mg}$ was administered to the patient intravenously in the morning as pre-operative medication. Soon after administration patient developed cough, breathlessness, chest tightness, wheeze, pink frothy sputum. Inj. Hydrocortisone, Inj. Adrenaline, Inj. Deriphylline and salbutamol nebulisation were administered and patient was immediately shifted to Intensive Care Unit as her condition deteriorated. Patient was intubated and ventilated.

In spite of intensive resuscitative measures, patient declared dead within minutes. Patient's tracheobronchial secretions were sent for histopathological examination. With the available facilities blood levels of ranitidine and presence of IgE against ranitidine could not be made out. Patient's attenders were not willing for autopsy. Histopathological examination of tracheobronchial secretions showed increased number of mast cells in supportive of anaphylaxis. With the collective history, clinical presentation and histopathological examination it can be concluded that death was out of anaphylactic reaction to Inj. Ranitidine since no other drug was given along with it and also patient had negative history of any allergy.

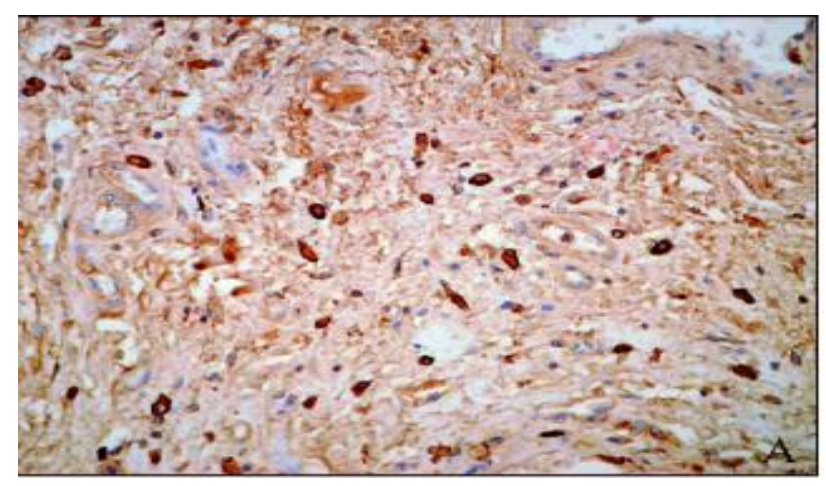

Figure 1: Histopathological report on tracheobronchial secretions-showing increased number of mast cells.

\section{DISCUSSION}

Ranitidine was commonly used $\mathrm{H} 2$ receptor antagonist in medical and surgical departments. The drug has been recalled in many countries after FDA warning because of the presence of NDMA (N-Nitrosodimethylamine) which is a potential carcinogen. Still countries like India continue to use ranitidine but with a caution and alerts taken during manufacturing process. $^{3}$ Anaphylactic reactions reported on ranitidine are very few, the incidence being $0.3-0.7 \% .^{4}$ Death due to ranitidine injection is the rarest. ${ }^{4}$ Demirkan et al had made out only 2 cases of anaphylactic reaction due to ranitidine of 8304 first referral patients over a 13 years period. ${ }^{5}$
Anaphylaxis in this patient was certainly due to Inj. Ranitidine as patient developed symptoms and signs of anaphylaxis soon after administration of the drug and she was not given any other medications along with ranitidine. Management was directed towards the anaphylactic reactions as was done in all reported reactions prior. ${ }^{2}$ This takes clinicians to surprise.

Research on Adverse drug reactions which are very rare but unpreventable of a relatively safe drug is meagre. Hence research on this area should be promoted. Also history on drug allergy and its proper documentation in patient's record is essential to avoid administration of the same drug in future.

\section{CONCLUSION}

Caution should be exercised even for administering medications with safer profile like administering prior test dose. Also, protocols should be formulated to prevent such deaths. Health planners and Hospital Personnel should work together to increase ADR monitoring and Pharmacovigilance reporting.

Funding: No funding sources Conflict of interest: None declared

Ethical approval: Not required

\section{REFERENCES}

1. Oliva A, Partemi S, Arena V, De Giorgio F, Colecchi $\mathrm{C}$, Fucci $\mathrm{N}$ et al. Fatal injection of ranitidine: a case report. J Med Case Rep. 2008;2:232.

2. Rethnam U, Yesupalan S. Anaphylactic reaction associated with Ranitidine in a patient with acute pancreatitis: a case report. J Med Case Reports. 2007;1(1):75.

3. U.S. Food and Drug. FDA Updates and Press Announcements on NDMA in Zantac (ranitidine). Available from: http://www.fda.gov/drugs/drugsafety-and-availability/fda-update Accessed on 4 March 2020.

4. Chopra D, Arora P, Khan S, Dwivedi S. Anaphylaxis following ins and press-announcements ndma zantac ranitidine intravenous ranitidine: $A$ rare adverse reaction of a common drug. Indian $\mathrm{J}$ Pharmacol. 2014;46(2):234-36.

5. Demirkan K, Bozkurt B, Karakaya G, Kalyoncu F. Anaphylactic reaction to drugs commonly used for gastrointestinal system diseases: 3 case reports and review of the literature. J Investig Allergol Clin Immunol. 2006;16(3):203-9.

Cite this article as: Anandhi S, Mani R. Injection ranitidine induced death. Int J Basic Clin Pharmacol 2020;9:1607-8. 